Reprod. Nutr. Dévelop., 1988, 28 Suppl. n¹, 119-120

\title{
Composition en acides aminés du flux d'azote entrant dans le duodé- num chez la vache laitière
}

L. LE HENAFF, H. RULQUIN, J. L. PEYRAUD

Station de Recherches sur la Vache laitière

I.N.R.A., Saint Gilles, 35590 L'Hermitage, France.

Summary. Effects of diet on amino acid (AA) composition of duodenal content were tested in high yielding dairy cows. For the same non-ammonia nitrogen flow $(491 \mathrm{~g} / \mathrm{d})$ hay diet gave higher contents in lysine, valine and leucine than maize silage diet. To predict such differences, an attempt is made to estimate duodenal AA content from the AA content of dietary or "by pass » proteins and from recent data on protein digestion.

Après avoir mesuré, sur des vaches fortes productrices, l'effet du type de ration sur la composition en acides aminés (AA) du flux de protéines entrant dans le duodénum, nous avons essayé de savoir si il était possible de le prédire. Pour cela, nous avons comparé les mesures à des compositions calculées à partir d'estimations des quantités et des compositions des trois catégories de protéines constitutives de ce flux.

Matériel et méthodes. Les mesures ont été effectuées sur 10 vaches produisant environ $30 \mathrm{~kg}$ de lait/j munies de canules sur le rumen et à l'entrée du duodénum. Cinq vaches ont ingéré (en matière sèche) $19,3 \mathrm{~kg} / \mathrm{j}$ d'une ration comportant $65 \%$ d'ensilage de maïs, $26 \%$ d'un concentré riche en parois cellulaires et $9 \%$ de tourteau de soja. Les autres ont ingéré $17,7 \mathrm{~kg} / \mathrm{j}$ d'une ration composée de $55 \%$ de foin de ray-grass anglais, $43,6 \%$ d'un concentré riche en amidon et 1,4\% de tourteau de soja. La composition des concentrés a été donnée par Le Hénaff et al. (1988). Le flux d'azote non ammoniacal (NNA) et sa composition en AA ont été déterminés sur un échantillon reconstitué pour chaque vache suivant la technique du double marquage (P.E.G., Ytterbium) (Peyraud, 1987).

Par ailleurs, les estimations de composition en AA ont été calculées en affectant aux quantités des protéines d'origine microbienne, endogène et alimentaire entrant dans le duodénum, prédites d'après l'équation donnée par Vérité et al. (1987), la composition en AA donnée par Ørskov (1982) et Ørskov et al. (1986) pour les microbes et l'endogène respectivement et celle de l'azote ingéré ou non dégradé après 16 h d'incubation dans le rumen (Le Hénaff et al., 1988).

Résultats et discussion. Le flux duodénal de NNA a été le même $(491 \pm 17 \mathrm{~g} / \mathrm{j})$ pour les deux rations et les coefficients de variation de ses teneurs en méthionine, arginine, histidine et phénylalanine ont été 2 à 3 fois plus élevés que ceux des autres AA (tabl. 1). Avec la ration à base de foin, le NNA duodénal 
a été significativement $(P<0,05)$ plus riche en lysine, leucine, valine et plus pauvre en AA non indispensables qu'avec de l'ensilage de maïs (tabl. 1). Cela reflète, en accord avec une étude bibliographique réalisée sur 200 rations, les différences de composition en AA des deux rations. Les compositions calculées à partir de la composition en AA des protéines ingérées ou non dégradées dans le rumen sont relativement proches l'une de l'autre (tabl. 1). Comparées aux

TABL. 1. - Effets mesurés ou calculés de la ration sur la composition en acides aminés du flux d'azote non ammoniacal entrant dans le duodénum.

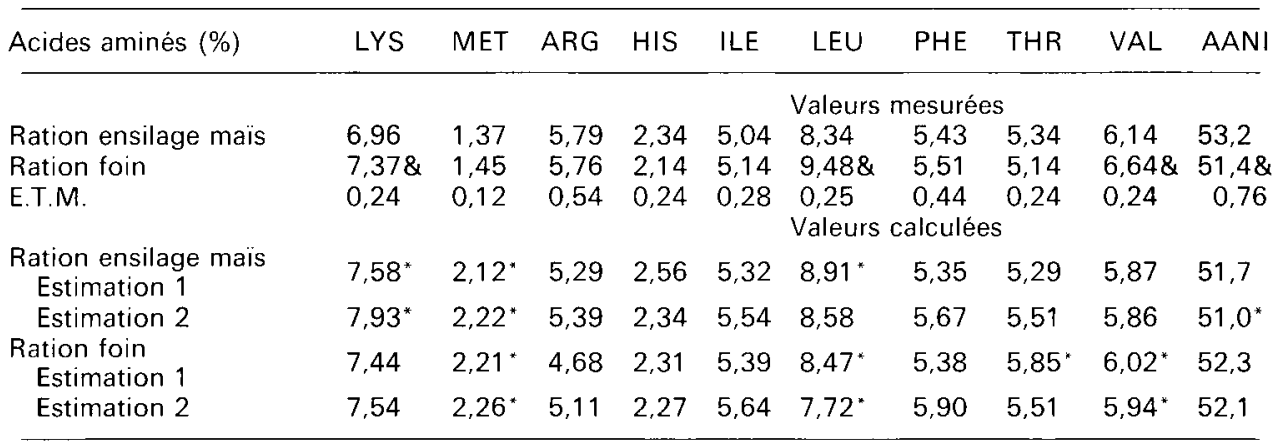

$\mathrm{AA}=$ acides aminés $; \mathrm{AANI}=\mathrm{AA}$ non indispensables; E.T.M $=$ écart type d'une moyenne $; \&=$ différent à $P<0,05$. Estimation 1 : calcul avec la composition en AA des aliments. Estimation 2 calcul avec la composition en AA du résidu alimentaire non dégradé après $15 \mathrm{~h}$ dans le rumen. * calcul différent de la mesure à $\mathrm{P}<0,05$.

mesures, ces estimations sont trop élevées pour la méthionine et la lysine $(+56$ et $6 \%$ ). Elles ne permettent donc pas, de prévoir correctement les différences entre rations sur ces deux AA qui peuvent être limitants pour les vaches laitières. Ces divergences peuvent provenir des différences éventuelles dans les techniques de dosage des AA utilisées pour déterminer la composition des trois catégories de protéines, de la non-représentativité des compositions retenues pour les fractions microbienne (différences entre bactéries libres et liées) et endogène (variations suivant le niveau d'ingestion).

La détection d'un mauvais équilibre des $A A$ fournis par la ration nécessite d'affiner les connaissances sur la composition en AA des trois catégories de protéines entrant dans le duodénum.

Le Hénaff L., Rulquin H., Peyraud J. L., 1988. Reprod. Nutr. Dévelop., 28, suppl. n 1, 133-134. Peyraud J. L., 1987. Reprod. Nutr. Dévelop., 27, 223-224.

Orskov E. R., 1982. In Protein nutrition in ruminants. Acad. Press (London) Ltd., pp. 160.

Orskov E. R., MacLeod N. A., Kyle D. J., 1986. Br. J. Nutr., 56, 2412-2418

Vérité R., Michalet-Doreau Brigitte, Chapoutot P., Peyraud J. L., Poncet C., 1987. Bull. Tech. CRZV Theix, I.N.R.A., 70, 19-34. 